\title{
Predicting the tumor response to radiotherapy using microarray analysis (Review)
}

\author{
KAZUHIKO OGAWA ${ }^{1,2}$, SADAYUKI MURAYAMA ${ }^{1}$ and MASAKI MORI ${ }^{2}$ \\ ${ }^{1}$ Department of Radiology, University of the Ryukyus, Okinawa; ${ }^{2}$ Department of Molecular and Surgical \\ Oncology, Medical Institute of Bioregulation, Kyushu University, Beppu, Japan
}

Received June 11, 2007; Accepted July 19, 2007

\begin{abstract}
Predicting the tumor response to radiotherapy is one of the major goals of human cancer treatment. Identification of the genes that are differentially expressed between radiosensitive and radioresistant cancers by global gene analysis may provide new insights into the mechanisms underlying clinical radioresistance and improve the efficacy of radiotherapy. In this study, we reviewed the published reports identifying sets of discriminating genes using microarray analysis that can be used for characterization and the prediction of response to radiotherapy in human cancers. These reports indicate that many of the identified genes were associated with DNA-repair, apoptosis, growth factor, signal transduction, cell cycle and cell adhesion. Several genes were found to be predictors of the radiation response with various cancers and certain sets of identified genes were also found to predict the radiation response by using clustering analysis. Global gene expression profiling of responders and nonresponders can be useful in predicting responses to radiotherapy and may also provide insights into the development of individualized therapies and novel therapeutic targets.
\end{abstract}

\section{Contents}

1. Introduction

2. Microarray analysis comparing radiosensitive and radioresistant cancer samples and cancer cell lines

3. Summary of the identified genes from cancer cell lines investigated by microarray

\section{Introduction}

Radiotherapy is one of the major treatments for patients with various cancers. The general rationale for radiotherapy is based on the findings that radiation can inhibit cell proliferation

Correspondence to: Dr Kazuhiko Ogawa, Department of Radiology, University of the Ryukyus School of Medicine, 207 Uehara, Nishihara-cho, Okinawa, 903-0215, Japan

E-mail: kogawa@med.u-ryukyu.ac.jp

Key words: radiotherapy, tumor response, radiosensitive, radioresistant or induce apoptotic cell death in vitro and inhibit tumor growth in vivo (1). However, the tumor response to radiotherapy sometimes differs among individual tumors even with the same histological field, and the lack of knowledge regarding the determinants of response has handicapped the development of predictive assays and the development of novel treatment strategies. Therefore, identification of the determinants of the tumor response to radiation has long been a goal of radiation oncologists and biologists.

Recently, an association between radioresistance and the expression of several genes was observed, with candidate genes, such as p53 (2), ras (3), raf-1 (4), bcl-2 (5) and survivin (6). Furthermore, cancer stem cells have emerged as a contributor to radioresistance through the preferential activation of the DNA damage checkpoint response and an increase in DNA repair capacity (7). Although such discoveries have helped develop a partial understanding of the molecular mechanisms responsible for cellular radiosensitivity, the entire process remains to be elucidated. The advent of microarray gene expression technology permits simultaneous analysis of the expression levels of thousands of genes (8-10). Therefore, a study on molecular genetic events related to radiosensitivity can be conducted. This research can lead to the identification of gene regulatory pathways that result in the development of resistance to therapeutic procedures. To date, differential gene expression profiles of radioresistant cancers and cancer cell lines such as breast cancer, esophageal cancer and uterine cervical cancer were observed using microarray analysis (11-13).

With a focus on the prediction of radiosensitivity by using microarray analysis, this review summarizes preclinical and clinical data in both human cancer and cancer cell lines by comparing radiosensitive and radioresistant cell lines. To identify suitable publications, a search strategy was defined as follows. The Medline database was used by entering all possible combinations from one of the following key words; 'radiosensitivity/radiosensitive/radioresistant/radiation/ radiotherapy,' with 'microarray'.

\section{Microarray analysis comparing radiosensitive and radioresistant cancer samples and cancer cell lines}

Presently, there are 17 reports comparing the gene expression profiles of radiosensitive and radioresistant cancer samples and cancer cell lines using microarray analysis. The site of 
these analyses are uterine cervical cancer (4 studies), head and neck cancer (3 studies), colorectal cancer (2 studies), breast cancer (1 study), esophageal cancer (1 study), pancreatic cancer ( 1 study), lung cancer ( 1 study), glioblastoma (1 study), hepatocellular carcinoma (1 study) and choroidal melanoma (1 study) (11-27).

Uterine cervical cancer. Kitahara et al compared gene expression profiles of 9 radiosensitive and 10 radioresistant tumors obtained by biopsy before treatment on a cDNA microarray consisting of 23,040 human genes (13). They identified 121 genes whose expression was significantly greater in radiosensitive cells than in radioresistant cells and 50 genes that reported higher levels of expression in radioresistant cells compared to radiosensitive cells. They discovered that genes involved in adipogenesis $(A L D H 1)$ and mitogen-activated protein kinase pathway (MAP3K2) were significantly upregulated in the responder group, while genes that are associated with the repair of breaks in double-strand DNA (XRCC5) were downregulated. The validity of the total 171 genes as being radiosensitivity-related genes was classified by the permutation test $(\mathrm{p}<0.05)$. Furthermore, they selected 62 genes on the basis of a clustering analysis and confirmed the validity of these genes with a cross-validation test. The cross-validation test also indicates the possibility of making a prediction of radiosensitivity for discriminating radiationsensitive from radiationresistant biopsy samples by predicting score values calculated from the expression values of 62 genes in 19 samples. Later, Harima et al conducted a subsequent follow-up analysis of Ku80 levels (gene product of XRCC5) in 89 cervical cancer patients and they found that the low $K u 80$ protein expression correlated well with sensitivity to radiation (28).

Additionally, Harima et al identified a set of genes related to thermoradiosensitivity of cervical cancer (14). They compared the expression profiles of 8 thermoradiosensitive and 11 thermoradioresistant tumors obtained by biopsy before treatment using a cDNA microarray consisting of 23,040 genes. They selected 35 genes on the basis of a clustering analysis and confirmed the validity of these genes with a cross-validation test. Some of these identified genes were associated with apoptosis such as BCL2-interacting killer $(B I K)$, testis-enhanced gene transcript (TEGT), STAT induced STAT inhibitor 3 (SSI-3); hypoxia-inducible genes such as hypoxia-inducible factor $1 \alpha(H I F 1 A)$, carbonic anhydrase XII $(C A 12)$ and some with tumor cell invasion and metastasis such as cathepsin L (CTSL), cathepsin B (CTSB), plasminogen activator urokinase (PLAU) and CD44 antigen (CD44).

In uterine cervical cancer, Tewari et al conducted a feasibility study of integrating an in vitro chemo-radiation response assay with a gene microarray system to investigate the molecular patterns of expression that contribute to radiation resistance in uterine cervical caner (15). Viable primary untreated cervical cancer specimens were obtained and exposed to $\gamma$ irradiation at a dose of $3 \mathrm{~Gy}$. Gene expression analysis was performed and the tumors were classified into extreme, intermediate and low radiation resistance categories. An intrinsic radiation response gene set of 54 gene transcripts with $100 \%$ accuracy for the classification of each tumor's radiation response category was identified. They concluded that gene sets associated with in vitro radiation response profiles in cervical cancer can be generated using the in vitro chemo-radiation response assay and microarray technology.

Wong et al analyzed 16 patients with invasive squamous cell carcinoma of the uterine cervix, with total RNA extracted from tumor specimens, hybridized onto an oligonucleotide microarray consisting of over 20,000 transcripts (16). The genes were subjected to a statistical filter to identify statistically significant differential expression levels between those that were radiosensitive and those that were radioresistant. A backpropagation neural network was then constructed to model the differences so that patterns could be easily identified. Using the expression of the 10 most discriminating genes, they found that neural networks constructed from random subsets of the whole data were capable of predicting radiotherapy responses in the remaining subset, which appears stable within the dataset. They concluded that such an approach has the potential to differentiate tumor radiosensitivity, although confirmation of such a pattern using other larger independent datasets is necessary before a firm conclusion can be drawn.

Head and neck cancer. Higo et al conducted a microarray analysis of 2,201 genes using human oral squamous cell carcinoma cell lines (HSC2 as radioresistant and HSC3 as radiosensitive). They found 7 overexpressed genes in the radioresistant cell line and 2 over-expressed genes in the radiosensitive cell line (17). Of these, expression of Tcomplex protein 20 (Tcp20), which belongs to a family of molecular chaperones, was remarkably elevated in radioresistant HSC2 cells after irradiation. Other identified genes function as angiogenetic modulators such as heparinbinding protein 17 ( $H B P 17)$ and catalysis of the cis to transisomerization (Cyclophilin $F$ ) was upregulated in radioresistant genes.

Ishigami et al compared gene expression signatures between oral squamous cell carcinoma cell lines exhibiting radioresistance and cells with radiosensitivity after X-ray irradiation in a dose-dependent manner using Affymetrix GeneChip analysis with Human Genome-U133 plus 2.0 GeneChip (18). The microarray data identified 167 genes that were significantly overexpressed in radioresistant cells after $\mathrm{X}$-ray irradiation. Among the genes identified, 40 were mapped to 3 highly significant genetic networks identified by the Ingenuity Pathway Analysis tool. The 40 genes included 25 cancer-related genes that formed 1 network and were categorized by function into growth and proliferation, apoptosis and adhesion i.e., cyclooxygenase 2 (COX-2), intercellular adhesion molecule 2 (ICAM2), matrix metalloproteinase 13 (MMP13) and inhibitor of DNA binding 3 (ID3). They concluded that the identified genes help to elucidate the molecular mechanisms of the radioresistance of oral squamous cell carcinoma and can be radiotherapeutic molecular markers for choosing the appropriate radiotherapy for this disease.

Concerning clinical samples, Hanna et al utilized Atlas Human Cancer cDNA Expression Arrays to analyze the expression profiles of 1187 tumor-related genes in radiationresistant and radiation-sensitive tissues (12). Sixty tumor- 
related genes were selected as predictors of the radiation response of squamous cell carcinomas of the head and neck. These genes included some of the classically known radiation-responsive genes such as $c$-jun and XRCC1. Using the expression intensities of these 60 tumor-related genes, in combination with cluster analysis, they successfully predicted the radiation identity of two tumor samples.

Colorectal cancer. Ghadimi et al compared the global gene expression differences between radiation responders and nonresponders with rectal cancer (19). Pre-treatment tumor biopsies from 30 patients who were randomized to receive radiotherapy and chemotherapy as part of the German Rectal Cancer Study (29) were studied and tumor response and a T-stage change. Using class comparison analysis between gene expression profiles from an initial run of 23 responsive or non-responsive tumors, 54 genes that were differentially expressed at significant levels were identified. Some of the genes are associated with DNA repair pathways (SMC1) and microtubule organization (CDC42 binding protein A [cdc42BPA], Filamin B). The ability to use these gene expression profiles to predict a response was then assessed using leave-one-out cross-validation. This generated an algorithm that allowed tumor behavior to be predicted with $78 \%$ sensitivity and $86 \%$ specificity. This algorithm was then further verified using a further 7 tumor samples hybridized on an alternative cDNA microarray platform which was able to correctly predict the response in 6 out of 7 patients. They concluded that pre-therapeutic gene expression profiling may assist in response prediction of rectal adenocarcinomas to preoperative chemoradiotherapy.

Watanabe et al constructed a new model using global gene expression profiling to predict the response to radiotherapy in rectal cancer (20). Using the human U95Av2 Gene Chip, they identified 33 novel discriminating genes of which the expression differed significantly between responders and nonresponders. Using this gene set, they were able to establish a new model to predict responses to radiotherapy in rectal cancer with an accuracy of $82.4 \%$. The list of discriminating genes included genes related to growth factors, apoptosis, cell proliferation, signal transduction and cell adhesion-related genes. The list of genes included the teratocarcinoma-derived growthfactor 3 (TDGF3), rho family member ( $R A C 2)$, signal transduction protein tyrosine kinase (TYRO3) and cell proliferation phosphoserine phosphatase-like (PSPHL). Among the 33 discriminating genes, apoptosis inducers such as Lumican (LUM), thrombospondin 2 (THBS2) and galectin 1 (LGALS1) reported a higher expression in responders whereas apoptosis inhibitors such as cyclophilin $40(C Y P D)$ and glutathione peroxidase 2 (GPX2) showed higher expression in non-responders. The authors concluded that this model may be predicted to offer a new strategy for tailored therapy in rectal cancer.

Breast cancer. Helland et al analyzed the gene expression microarray analysis from the samples of 19 breast cancer patients before and after radiotherapy (2 Gy x 10 fractions) (21). They found that several genes involved in cell cycle regulation and DNA repair such as glutathione peroxidase 1 (GPX1); apoptosis, DNA binding protein 2 (DDB2); signal transduction, growth/differentiation factor 15 (GDF15); and cell cycle, cyclin-dependent kinase inhibitor 1A (CDKN1A) were significantly induced by radiation treatment. They also found that mutations were found in the p53 gene in 39\% of the tumors and the observed gene expression profiles seemed to be influenced by the $p 53$ mutation status.

Esophageal cancer. Fukuda et al established 4 radioresistant esophageal cancer cell lines by applying fractionated irradiation and compared the gene expression profiles of each parent and radioresistant line on cDNA microarrays consisting of 21,168 genes (11). They identified 19 upregulated genes and 28 downregulated genes common to radioresistant sublines. Upregulated genes were associated with apoptosis and inflammatory responses baculoviral IAP repeat-containing 2 (BIRC2,COX-2), DNA metabolism $(C D 73)$ and cell growth (PLAU). Downregulated genes were associated with apoptosis such as caspase 6 (CASPO); cell adhesion $(\mathrm{CDH1})$, transcription mixed-lineage leukemia 3 (MLL3); and cell cycle, cyclin-dependent kinase 6 (CDKO). Some of these genes were known to be associated with the radiation response, such as $C O X-2$, but others were novel. They also examined the effect of radiotherapy on the expression of selected genes in clinical specimens. In 8 cases of squamous cell carcinoma of the esophagus, they found that the expression rates of $\mathrm{BIRC} 2$ for patients whose histological grade after radiotherapy (RT) was either 0 or 1 were significantly higher than those for patients whose histological grade after RT was either 2 or 3.

Pancreatic cancer. Ogawa et al established 5 radioresistant pancreatic cancer cell lines by applying fractionated irradiation and compared the gene expression profiles of each parent and radioresistant line on a oligonucleotide microarrays consisting of 17,086 genes (22). They identified 73 upregulated genes and 55 down-regulated genes common to radioresistant sublines. Upregulated genes were associated with growth factor signaling such as amphiregulin (AREG) and cell cycle checkpoints MAPK-activated protein kinase 2 (MAPKAPK2), intracellular signaling pathways (regucalcin) and angiogenic stimulation angiopoietin 2 (ANGPT2), whereas downregulated genes were associated with apoptosis such as caspase $8(C A S P 8)$, retinoid esterification (LRAT) lecithin retinol acyltransferase and electron transport calcium-activated chloride 1 (CACC1). In particular, some of the identified genes such as CASP 8 and MAPKAPK2 were known to be associated with a responsiveness to radiation.

Lung cancer. Guo et al compared 2 lung cancer cell lines with different radiosensitivity (NCI-H446 and A549, which is more radioresistant than NCI-H446) using oligonucleotide microarrays consisting of 143 genes (23). They found that the identified genes, such as TP53, were associated with apoptosis and cell proliferation, such as MDM2 and $\mathrm{Bcl}$-2, whose expression levels were increased in A549 (radioresistant) cells and decreased in NCI-H446 (radiosensitive) cells after irradiation. They also found that genes involved in DNA repair, such as XRCC5 and the gene encoding DNA-PK, were found to be increased to a higher level in radioresistant A549 cells than in radiosensitive NCI-H446 cells. 
Table I. Representative candidate genes related to radiosensitivity identified by microarray analysis.

\begin{tabular}{|c|c|c|c|c|c|c|c|c|c|c|}
\hline $\begin{array}{l}\text { Site } \\
\text { (Ref.) }\end{array}$ & $\begin{array}{l}\text { DNA- } \\
\text { repair }\end{array}$ & Apoptosis & $\begin{array}{l}\text { Growth } \\
\text { factor }\end{array}$ & $\begin{array}{c}\text { Signal } \\
\text { transduction }\end{array}$ & $\begin{array}{l}\text { Cell } \\
\text { cycle }\end{array}$ & $\begin{array}{c}\text { Cell } \\
\text { adhesion }\end{array}$ & $\begin{array}{l}\text { Invasion and } \\
\text { metastasis }\end{array}$ & Angiogensis & $\begin{array}{c}\text { Hypoxia } \\
\text {-related }\end{array}$ & Others \\
\hline $\begin{array}{l}\text { Uterine } \\
\text { cervix } \\
(13-16)\end{array}$ & XRCC5 & $\begin{array}{c}\text { BIK } \\
\text { SSI-3 }\end{array}$ & & MAP3K2 & & & $\begin{array}{l}\text { CTSL } \\
\text { PLAU }\end{array}$ & & $\begin{array}{l}\text { HIF1A } \\
\text { CA12 }\end{array}$ & ALDH1 \\
\hline $\begin{array}{l}\text { Head and } \\
\text { neck } \\
(12,17,18)\end{array}$ & XRCC1 & ICAM2 & $\mathrm{COX} 2$ & c-JUN & & $\begin{array}{c}\text { MMP13 } \\
\text { ID3 }\end{array}$ & & HBpl7 & & ТCP20 \\
\hline $\begin{array}{l}\text { Colon and } \\
\text { rectum } \\
(19,20)\end{array}$ & $\begin{array}{c}\text { SMC1 } \\
\text { THBS2 }\end{array}$ & $\begin{array}{l}\text { THBS2 } \\
\text { GPX2 }\end{array}$ & $\begin{array}{l}\text { PSPHL } \\
\text { TDGF3 }\end{array}$ & $\begin{array}{l}\text { RAC2 } \\
\text { TYR03 }\end{array}$ & & CDC42BPA & & & & \\
\hline $\begin{array}{l}\text { Breast } \\
(21)\end{array}$ & DDB2 & GPX1 & & GDF15 & CDKN1A & & & & & \\
\hline $\begin{array}{l}\text { Esophagus } \\
\text { (11) }\end{array}$ & & $\begin{array}{l}\text { CASP6 } \\
\text { BIRC2 }\end{array}$ & $\mathrm{COX} 2$ & MLL3 & CDK6 & $\mathrm{CDH} 1$ & PLAU & & & $\mathrm{CD} 73$ \\
\hline $\begin{array}{l}\text { Pancreas } \\
(22)\end{array}$ & & CASP8 & AREG & Regucalcin & $\begin{array}{c}\text { MAPKAPK2 } \\
\text { cyclin Al }\end{array}$ & & & AGPT2 & & LRAT \\
\hline $\begin{array}{l}\text { Lung } \\
(23)\end{array}$ & XRCC5 & TP53 & $\begin{array}{c}\text { MDM2 } \\
\text { Bcl-2 }\end{array}$ & & & & & & & \\
\hline $\begin{array}{l}\text { Glioblastoma } \\
\text { (24) }\end{array}$ & $\begin{array}{l}\text { XRCC5 } \\
\text { G22P1 }\end{array}$ & & & & & & & & & \\
\hline $\begin{array}{l}\mathrm{HCC} \\
(25)\end{array}$ & $\begin{array}{c}\text { ERCC5 } \\
\text { PMS1 }\end{array}$ & & & & & & & & & \\
\hline $\begin{array}{l}\text { CLL } \\
(26)\end{array}$ & & & c-myc & $\begin{array}{c}\text { c-rel } \\
\text { c-IAPl }\end{array}$ & & & & & & HSP27 \\
\hline
\end{tabular}

HCC, hepatocellular carcinoma; CLL, chronic lymphocytic leukemia.

Glioblastoma. Otomo et al analyzed transcriptional changes after ionizing radiation in 2 glioblastoma cell lines with different radiosensitivities (24). Between the 2 cell lines, the differences in the percentage of genes involved in DNA repair/replication was the largest and this category was present at a larger percentage in the radioresistant cell line. These genes included the KRCC5 and G22Pl (Ku70) genes, known to be important members of the non-homologous endjoining pathway of DNA double-strand break repair. They concluded that the distribution of genes represented in the DNA repair/replication category was most different between the two human glioblastoma cell lines of different radiosensitivities.

Hepatocellular carcinoma. Jeoung et al evaluated the expression profiles of radiation-responsive genes in human hepatocellular carcinoma through time-dependent cDNA microarray analysis following exposure to ionizing radiation (25). In their study, DNA repair-promoting genes (such as ERCC and PMS1) were upregulated in radioresistant cells and downregulated or unchanged in radiationsensitive cells. They concluded that DNA repair capacity may control the radiation sensitivity of human hepatocelular carcinoma cells more than any other physiological factor.
B-cell chronic lymphocytic leukemia. Vallat et al (26) conducted a microarray analysis of the responses of B-cell chronic lymphocytic leukemia cells that were both sensitive (4 samples) and resistant (3 samples) to radiation. Sixteen genes were differentially regulated by at least 2 -fold specifically in the resistant cells and they confirmed their altered expression levels in 15 additional B-cell chronic lymphocytic leukemia samples not included in the microarray analysis. These identified genes included $c-m y c$, $c$-rel, and $c$-IAP1; 2 of these genes, $c$-rel and $c$-IAPl, have direct connections to the NF- $\mathrm{KB}$ pathway (30). Resistant cells also had downregulated genes, including stat 1 and heat shock protein 27 (HSP27), in spite of differences in p53 status. These results suggest that these differentially expressed genes may be of clinical relevance and can also be used as prognostic indicators in patients with B-cell chronic lymphocytic leukemia.

Malignant melanoma. Kuamgai et al analyzed choroidal malignant melanoma cell lines using an oligonucleotide microarray containing 10,800 genes (27). They found 34 genes that were differentially expressed in the OCM-1 and OCM-2 cell lines (radioresistant) compared with the 92-1 cell line (radiosensitive). They selected 13 genes that were 
confirmed by RT-PCR and investigated the correlation between gene expression and SF2 (surviving fraction at 2 Gy irradiation) using Pearson's correlation coefficient and the Fisher's Exact test on the 13 genes. Of these genes, the actin polymerization-related gene actin related protein $2 / 3$ complex $41 \mathrm{kd}$ (Arpclb) was found to be a candidate predictive marker for radiation sensitivity of choroidal malignant melanoma.

\section{Summary of the identified genes from cancer cell lines investigated by microarray}

These reports have indicated that the majority of the identified genes relating to radiosensitivity in human cancer have been associated with apoptosis, DNA-repair, growth factor, signal transduction, cell cycle and cell adhesion, invasion and metastasis, angiogenesis and hypoxia (Table I). Some of the genes, such as $B I R C 2$, were to be a predictor of the radiation response in human cancer. Moreover, several groups demonstrated that gene analysis is able to predict the tumor response to radiotherapy in several cancer types.

In conclusion, this review, along with previous reports, indicates that genes related to radiosensitivity are frequently associated with DNA repair, apoptosis, growth factor, signal transduction, cell cycle and cell adhesion. Therefore, these genes can contribute to radioresistance in many cancer types. Our review also confirmed that several genes were found to be predictors of the radiation response with various cancers and certain sets of identified genes were also found to predict the radiation response by using clustering analysis. Analyses of global gene expression profiling between radiation responders and non-responders can be useful in predicting the response to radiotherapy and can also provide insights into the mechanism and development of individual therapies and novel therapeutic targets.

\section{References}

1. Hendry JH and West CM: Apoptosis and mitotic cell death: their relative contributions to normal-tissue and tumor radiation response. Int J Radiat Biol 71: 709-719, 1997.

2. Biard DS, Martin M, Rhun YL, Duthu A, Lefaix JL and May P: Concomitant p53 gene mutation and increased radiosensitivity in rat lung embryo epithelial cells during neoplastic development. Cancer Res 54: 3361-3364, 1994.

3. Sklar MD: The ras oncogene increases the intrinsic resistance of NIH 3T3 cells to ionizing radiation. Science 239: 645-647, 1988.

4. Kasid U, Pfeifer A, Weichselbaum RR, Dritschilo A and Mark GE: The raf oncogene is associated with a radiationresistant human laryngeal cancer. Science 237: 1039-1041, 1987.

5. Lee JU, Hosotani R, Wada M, Doi R, Kosiba T, Fujimoto K, Miyamoto Y, Tsuji S, Nakajima S, Nishimura Y and Imamura M: Role of bcl-2 family proteins (Bax, Bcl-2, Bcl-X) on cellular susceptibility to radiation in pancreatic cancer cells. Eur J Cancer 35: 1374-1380, 1999.

6. Asanuma K, Moriai R, Yajima T, Yagihashi A, Yamada M, Kobayashi D and Watanabe N: Survivin as a radioresistant factor in pancreatic cancer. Jpn J Cancer Res 91: 1204-1209, 2000.

7. Bao S, Wu Q, McLendon RE, Hao Y, Shi Q, Hjelmeland AB, Dewhirst MW, Bigner DD and Rich JN: Glioma stem cells promote radioresistance by preferential activation of the DNA damage response. Nature 444: 756-760, 2006.

8. DeRisi J, Penland L, Brown PO, Bittner ML, Meltzer PS, Ray M, Chen Y, Su YA and Trent JM: Use of a cDNA microarray to analyse gene expression patterns in human cancer. Nat Genet 14: $457-460,1996$.
9. Eisen MB, Spellman PT, Brown PO and Botstein D: Cluster analysis and display of genome-wide expression patterns. Proc Natl Acad Sci USA 95: 14863-14868, 1998.

10. Golub TR, Slonim DK, Tamayo P, Huard C, Gaasenbeek M, Mesirov JP, Coller H, Loh ML, Downing JR, Caligiuri MA, Bloomfield CD and Lander ES: Molecular classification of cancer: class discovery and class prediction by gene expression monitoring. Science 286: 531-537, 1999.

11. Fukuda K, Sakakura C, Miyagawa K, Kuriu Y, Kin S, Yanase Y, Hagiwara A, Mitsufuji S, Okazaki Y, Hayashizaki Y and Yamagishi H: Differential gene expression profiles of radioresistant oesophageal cancer cell lines established by continuous fractionated irradiation. Br J Cancer 91: 1543-1550, 2004.

12. Hanna E, Shrieve DC, Ratanatharathorn V, Xia X, Breau R, Suen $\mathrm{J}$ and $\mathrm{Li} \mathrm{S}$ : A novel alternative approach for prediction of radiation response of squamous cell carcinoma of head and neck. Cancer Res 61: 2376-2380, 2001.

13. Kitahara O, Katagiri T, Tsunoda T, Harima Y and Nakamura Y: Classification of sensitivity or radioresistance of cervical cancers to ionizing radiation according to expression profiles of 62 genes selected by cDNA microarray analysis. Neoplasma 4: 295-303, 2002.

14. Harima Y, Togashi A, Horikoshi K, Imamura M, Sougawa M, Sawada S, Tsunoda T, Nakamura Y and Katagiri T: Prediction of outcome of advanced cervical cancer to thermoradiotherapy according to expression profiles of 35 genes selected by cDNA microarray analysis. Int J Radiat Oncol Biol Phys 60: 237-248, 2004.

15. Tewari D, Monk BJ, Al-Ghazi MS, Parker R, Heck JD, Burger RA and Fruehauf JP: Gene expression profiling of in vitro radiation resistance in cervical carcinoma: a feasibility study. Gynecol Oncol 94: 84-91, 2005

16. Wong YF, Sahota DS, Cheung TH, Lo KW, Yim SF, Chung TK, Chang AM and Smith DI: Gene expression pattern associated with radiotherapy sensitivity in cervical cancer. Cancer J 12: 189-193, 2006.

17. Higo M, Uzawa K, Kouzu Y, Bukawa H, Nimura Y, Seki N and Tanzawa H: Identification of candidate radioresistant genes in human squamous cell carcinoma cells through gene expression analysis using DNA microarrays. Oncol Rep 14: 1293-1298, 2005.

18. Ishigami T, Uzawa K, Higo M, Nomura H, Saito K, Kato Y, Nakashima D, Shiiba M, Bukawa H, Yokoe H, Kawata T, Ito H and Tanzawa $\mathrm{H}$ : Genes and molecular pathways related to radioresistance of oral squamous cell carcinoma cells. Int J Cancer 120: 2262-2270, 2007

19. Ghadimi BM, Grade M, Difilippantonio MJ, Varma S, Simon R, Montagna C, Fuzesi L, Langer C, Becker H, Liersch T and Ried T: Effectiveness of gene expression profiling for response prediction of rectal adenocarcinomas to preoperative chemoradiotherapy. J Clin Oncol 23: 1826-1838, 2006

20. Watanabe T, Komuro Y, Kiyomatsu T, Kanazawa T, Kazama Y, Tanaka J, Tanaka T, Yamamoto Y, Shirane M, Muto T and Nagawa H: Prediction of sensitivity of rectal cancer cells in response to preoperative radiotherapy by DNA microarray analysis of gene expression profiles. Cancer Res 66: 3370-3374, 2006.

21. Helland S, Johnsen H, Froyland C, Landmark HB, Saetersdal AB, Holmen MM, Gjertsen T, Nesland JM, Ottestad W, Jeffrey SS, Ottestad LO, Rodningen OK, Sherlock G and Borresen-Dale AL: Radiation-induced effects on gene expression: an in vivo study on breast cancer. Radiother Oncol 80: 230-235, 2006.

22. Ogawa K, Utsunomiya T, Mimori K, Tanaka F, Haraguchi N, Inoue $\mathrm{H}$, Murayama S and Mori M: Differential gene expression profiles of radioresistant pancreatic cancer cell lines established by fractionated irradiation. Int J Oncol 28: 705-713, 2006.

23. Guo WF, Lin RX, Huang J, Zhou Z, Yang J, Guo GZ and Wang SQ: Identification of differentially expressed genes contributing to radioresistance in lung cancer cells using microarray analysis. Radiat Res 164: 27-35, 2005.

24. Otomo T, Hishii M, Arai H, Sato K and Sasai K: Microarray analysis of temporal gene responses to ionizing radiation in two glioblastoma cell lines: up-regulation of DNA repair genes. J Radiat Res 45: 53-60, 2004.

25. Jeong J, Hong SJ, Ju YJ, Kim BY, Park MJ, Kim TH, Park CI, Choi KY, Cho MH, Kim SH, Lee H and Lee KH: Temporal cDNA microarray analysis of gene expression in human hepatocellular carcinoma upon radiation exposure. Oncol Rep 15: $33-48,2006$. 
26. Vallat L, Magdelenat H, Merle-Beral H, Masdehors P, Potocki de Montalk G, Davi F, Kruhoffer M, Sabatier L, Orntoft TF and Delic J: The resistance of B-CLL cells to DNA damage-induced apoptosis defined by DNA microarrays. Blood 101: 4598-4606, 2003.

27. Kuamgai K, Nimura Y, Mizota A, Miyahara N, Aoki M, Furusawa Y, Takiguchi M, Yamamoto S and Seki N: Arpclb gene is a candidate prediction marker for choroidal malignant melanomas sensitive to radiotherapy. Invest Opthalmol Vis Sci 47: 2300-2304, 2006.

28. Harima Y, Sawada S, Miyazaki Y, Kin K, Ishihara H, Imamura M, Sougawa M, Shikata N and Ohnishi T: Expression of ku80 in cervical cancer correlates with response to radiotherapy and survival. Am J Clin Oncol 26: e80-e85, 2003.
29. Sauer R, Fietkau R, Wittekind C, Martus P, Rodel C, Hohenberger W, Jatzko G, Sabitzer H, Karstens JH, Becker H, Hess $\mathrm{C}$ and Raab R: Adjuvant versus neoadjuvant radiochemotherapy for locally advanced rectal caner. A progress report of a phase-III randomized trial (protocol CAO/ARO/AIO-94). Strahlenther Onkol 177: 173-181, 2001.

30. Chen X, Shen B, Xia L, Khaletzkiy A, Chu D, Wong JY and Li JJ: Activation of nuclear factor kappaB in radioresistance of TP53-inactive human keratinocytes. Cancer Res 62: 1213-1221, 2002. 